\title{
Influence of Inoculum and Substrate Concentration on Anaerobic Digestion of Ocimum Sanctum (Holy Basil)
}

\author{
Dr Sumanth Kumar Matha, Post-Doctoral Scientist, Department of Environmental Sciences, \\ Andhra University, Visakhapatam, Andhra Pradesh, India.dr.msumath@gmail.com \\ Dr Korla Swapnavahini, Assistant Professor, Department of Biotechnology, Dr B.R. Ambedkar \\ University, Srikakulam, Etcherla, Andhra Pradesh, India. *Corresponding Author Email: \\ ksv_jr08@yahoo.com
}

\begin{abstract}
Anaerobic digestion is the constrained degradation of usual organic waste in the oxygen deficient environment and the existence of anaer0bic microorganisms. Anaerobic digestion is accomplished by microbial diversity. "Substrate loading rate is a measure of biological conversion capacity of anaerobic system and has significant influence on the process performance. Henceforth in the current work, the outcome of different concentrations of substrate to inoculum $(0.3,0.6$ and 0.9$)$ on anaerobic digestion of Holy Basil (Ocimum sanctum) used as substrate was explored in batch reactors for 45 days along with heterogenous cowdung as Inoculum. Temperature and biogas were noted daily. "The Volatile Solids (VS), Chemical Oxygen Demand (COD), Total Kjeldhal Nitrogen (TKN) and Phosphorous were analyzed at an interval of 5 days. Though the degradation rates of various parameters showed a higher efficiency at 0.3 inoculum to "substrate concentration, the biogas generation was impending to be maximum at
\end{abstract} 0.6 among the various digesters.

Keywords - Anaerobic digestion, Inoculum, Substrate, Holy Basil, COD, biogas

\section{INTRODUCTION}

Anaerobic digestion is considered a key technology for the future bio-based economy [1]. Biogas is produced through anaerobic digestion, which is a biological process in which organic material of a substrate is degraded by microorganisms in the absence of oxygen [2]. Anaerobic digestion is a biological treatment that entails a correct concentration of substrate and inoculum. The ideal balance to overcome the limitation of biomass and to avoid the overloading of organic matter has to be found. A limitation of anaerobes produces a slow methane production, meanwhile an excess of organic matter results in total inhibition of biomass activity or at least a lag phase for acclimation. In that manner, both situations result in a longer digestion time and consequently larger digesters [3].

Ocimum Sanctum is one of the main offering towards deities in Vaishanvite custom. A huge amount of waste $(900 \mathrm{~kg})$ is generated in the temples [4] which is not mixed with municipal solid waste as it is considered Holy and discarded on land or into water. Hence, it can be a source of decentralized energy generation process in Vaishnavite temples. Main aim of the current study was to assess the influence of the inoculum (cowdung) in the anaerobic biodegradation of Holy Basil (Ocimum sanctum) at varied substrate to inoculum concentrations.

\section{Methodology}

The leaves of Holy Basil (Ocimum sanctum), a herbaceous plant cultivated for religious and medicinal uses [5]. Holy Basil leaves are collected from "Simhachalam Temple, Visakhapatnam, where it is otherwise discarded as waste. Plant leaves are splashed with distilled water and the blended paste of air dried fresh leaves is used as a substrate. To each digester bottle, varied inoculum to substrate concentrations $(0.3,0.6$ and 0.9 ratio) were added and the experiment was designed [4].

A graduated glass bottles $2.5 \mathrm{~L}$ capacity with $1 \mathrm{~L}$ working volume, fitted with rubber cork to hold thermometer and $\mathrm{pH}$ electrodes is used as digester. Another graduated glass bottles $2.5 \mathrm{~L}$ capacity was used for gas collection that contained brine solution and was connected to the digester by means of a connecting tube. Also, on the other side, the gas collection bottle was connected to a conical flask by means of a connecting tube called as the collection bottle. Thus, the biogas produced in the digester is delivered through the linking tube to the gas collection bottle. "The 
pressure of the biogas produced caused a dislocation of brine solution over a connecting tube to other side into the conical flask [4].

Cowdung was mixed with blended leaves and stems of Holy Basil and water to get a ratio of 0.3, 0.6 and 0.9. The volumes were proportionate to obtain a final composition of $1000 \mathrm{~mL}$ of liquid. The incubation time was 45 days at room temperature. Biogas was measured by liquid displacement method [4]. "The contents of the digester were agitated daily manually for 5 minutes.

For the determination of endogenous biogas production, blanks containing only cowdung were done. The experiment include two sets of samples. One of the series included duplicate samples for each concentration and sampling time. This group of samples was sacrificed periodically for Solids, COD, nitrogen and phosphorous analysis [6]. Volatile Solids (VS) were determined by ignition of the residue to constant weight in a muffle furnace at a temperature of $550^{\circ} \mathrm{C}$. COD was determined by dichromate reflux method. Phosphorous was measured spectrophotometrically, Total Kjeldhal Nitrogen (TKN) was measured using Kjeldhal method as per standard method described by Eaton [6]. Meanwhile, the second set of samples were tracked for biogas in the 'headspace' over the digestion period.

\section{RESUlTS AND DisCUSSION}

Cow dung was chosen as inoculum as cowdung is a precious resource [7] and also with respect to philosophy, culture, religion, it is considered sacred. Discontinuous mixing is preferred to continuous blending because it increases biomass settling and reactor production [8], [9].

As was evident from fugure 1, a maximal biogas of 427 $\mathrm{m}^{3} /$ day is produced on day 3 with an mean of $96.51 \mathrm{~m}^{3} /$ day with 0.3 inoculum to substrate concentration. A $0.453 \mathrm{dm}^{3} / \mathrm{kg}$ was accumulated at 0.6 inoculum to substrate concentration. The biogas generation ranged between $10 \mathrm{~m}^{3}$ - $560 \mathrm{~m}^{3} /$ day with maximum production on day 9 . The mean biogas production was $139.88 \mathrm{~m}^{3} /$ day for equal inoculums to substrate concentrarion ratio of 0.9 . The observed results suggest that biogas potential was maximum for 0.6 inoculum to substrate concentration (Figure 1).

The steady state reduction in the Solids concentration has been revealed with every inoculum to substrate concentration .It has increased upto $73.52 \%, 57.99 \%$, $39.08 \%$ of VS at $0.3,0.6$ and 0.9 inoculum to substrate concentrations respectively by the end of 45 days. Among the three experimental set ups, Solids reduction was observed to be maximum with 0.3 inoculum to substrate concentration, followed by 0.6 and then 0.9 respectively. Volatile Solids (VS) in the digester decreased as the digestion period prolonged. The COD values were observed to decrease gradually throughout the digestion period under all the three substrate to inoculum concentrations. There was a steady decrease in COD till the end of retention time and after 45 days maximum reduction of $75.13 \%, 67.43 \%$, $47.69 \%$ of COD was shown by $0.3,0.6$ and 0.9 inoculum to loading rate respectively. Nitrogen and Phosphorous accumulation was utmost with 0.6 inoculum to substrate concentration when compared among the three experimental set ups. A raise of $17.25 \%$ and $27.46 \%$ Nitrogen and Phosphorous when compared with the initial was observed for 0.3 inoculum to substrate concentration. There was $44.36 \%$ Nitrogen and $38.31 \%$ Phosphorous content increase at 0.6 inoculum to substrate concentration. A total of only $15.76 \%$ and $24.16 \%$ of Nitrogen and Phosphorus increase were observed with 0.9 substrate concentration. There was a decrease in the Nitrogen and Phosphorus content in the feed initially and later on the concentration increased in all the digesters. The reduction in Nitrogen content at the start in the fermenter could be explained by conversion of Nitrogen to biomass or may be converted to gaseous Nitrogen [10]. With increased retention time, Nitrogen and phosphorus content increased in the feed which can be pinned to mineralization of blends containing organic Nitrogen and phosphorus [11]. The statistical values clearly substantiate the results which was clearly depicted in figure 2 .

The inoculum and substrate concentration was hiked from 0.3 towards 0.6 , there was an escalation in the biogas production amounting to 1.7 fold increase. Biogas production was higher at 0.6 inoculum toward substrate filling rate; though, with an increase in concentration to 0.9 , it has reduced. Similarly, the finest ratio of inoculum solid and the initial total solid at start-up was 0.5 to 0.6 [12]. Prolonged retention times were observed at low inoculum ratio due to a low leachate flow rate recycle. When the inoculum ratio reduced to 0.4 or lower, the standard retention time extended to 50 days and further due to the suboptimal conditions, such as lower $\mathrm{pH}$ and higher organic acid concentrations [13]. .

\section{CONClusion}

The outcomes from the study aid to apprehend the use of a specific substrate and inoculum concentrations to obtain an accurate control of the method. The effects of varied substrate and inoculum on anaerobic digestion were investigated with $0.3,0.6$ and 0.9 concentration. High biogas of $0.453 \mathrm{dm}^{3} / \mathrm{kg}$ was produced with 0.6 inoculum to substrate concentration. At higher concentration of 0.9 , the biogas production rates have been dropped. But the degradation rates of Solids, COD, Nitrogen and Phosphorous showed an incresed efficiency at 0.3 inoculum to substrate concentration. 


\section{REFERENCES}

[1]J. D. Vrieze, S. Gildemyn, R. Vilchez-Vargas, R. Jáuregui, D. H. Pieper, W. Verstraete, and N. Boon, "Inoculum selection is crucial to ensure operational stability in anaerobic digestion," Appl Microbiol Biotechnol, vol. 99, pp. 189-199, 2015

[2]I. Angelidaki, L. Ellegaard and B. K. Ahring, "Applications of the anaerobic digestion process," Adv. Biochem. Engg. Biotechnol., vol. 82, pp. 133, 2003.

[3]C. González-Fernández and P. A, García-Encina, "Impact of substrate to inoculum ratio in anaerobic digestion of swine slurry," Biomass and Bioenergy, vol. 33, no. 8, pp. 1065-1069, 2009

[4]S. P. Singh, M. Rathore and S. Tyagi, "Feasibility Study of Biogas Production From Flower Waste," IJEP, vol. 27, no. 7, pp. 597-603, 2007.

[5]J. M. A. Hannan, L. Marenah, L. Ali, B. Rokeya, P. R. Flatt and Y. H. A. Abdel-Wahab, "Ocimum sanctum leaf extracts stimulate insulin secretion from perfused pancreas, isolated islets and clonal pancreatic -cells," Journal of Endocrinology, vol. 189, pp. 127-136, 2006

[6] A. D. Eaton, L. S. Clesceri, E. W. Rice and A. E. Greenberg, "Standard Methods for the Examination of Water and Wastewater". $21^{\text {st }}$ Edition. American Public Health Association (APHA), Washington DC, USA, 2005.

[7]G. K. Randhawa. and J. S. Kullar, "Bioremediation of Pharmaceuticals, Pesticides, and Petrochemicals with Gomeya/Cow Dung," ISRN (International Scholarly Research Network) Pharmacology, 2011; 7 pages, Article ID 362459 , doi:10.5402/2011/362459.

[8]D. I. Masse and L. Masse, "Treatment of Slaughterhouse Wastewater in Anaerobic Sequencing Batch Reactors,".Canadian Agricultural Engineering, vol. 42, no. 3, pp. 131 137, 2000.

[9]S. Sung and R. R. Dague, "Laboratory Studies on the Anaerobic Sequencing Batch Reactor," Water Environment Research, vol. 67, pp. 294 - 301, 1995.

[10] S. Beux, E. Nunes and A. C. Barana, "Effect of Temperature on Two- phase Anaerobic Reactors Treating Slaughterhouse Wastewater," Brazilian Archives of Biology and Technology, vol. 50, no. 6, pp. 1061 - 1072, 2007.

[11] J. Coombs, "The Present and Future of Anaerobic Digestion: A Waste Treatment Technology," Elsevier Science Publishers, London,1994.
[12]E. T. Brummeler, M. M. J. Aarnink, and I. W. Koster, "Dry anaerobic digestion of solid organic waste in a BIOCEL reactor at pilot-plant scale," Water Sci. Technol., vol. 25, no. 7, pp. 301-310, 1992.

[13] A. K. Jha, J. Li, L. Nies and L. Zhang, "Research advances in dry anaerobic digestion process of solid organic wastes," African Journal of Biotechnology, vol. 10, no. 65, pp 14242-14253, 2011.

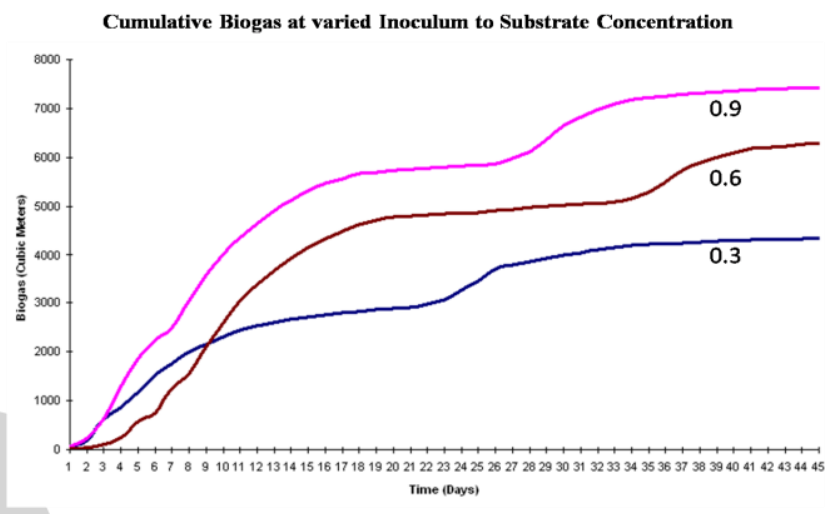

Figure 1: Comparison of cumulative biogas at varying inoculum and Substrate concentration

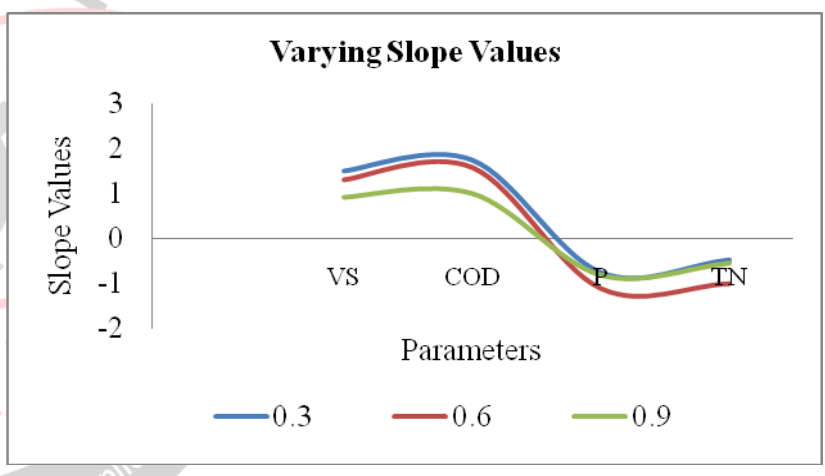

Figure 2: Slope values at varying substrate and inoculum concentrations 